\title{
Differences in demographics and outcomes based on method of consent for a randomised controlled trial on heat loss prevention in the delivery room
}

\author{
Sunita Vohra (1) , 1 Maureen Reilly, ${ }^{2}$ Valeria E Rac, ${ }^{2,3}$ Zafira Bhaloo, ${ }^{1}$ Denise Zayak, ${ }^{4}$ \\ John Wimmer, ${ }^{5}$ Michael Vincer, ${ }^{6}$ Karla Ferrelli, ${ }^{4}$ Alex Kiss, ${ }^{3,7}$ Roger Soll, ${ }^{4,8}$ \\ Michael Dunn ${ }^{2,9}$
}

For numbered affiliations see end of article.

\section{Correspondence to} Maureen Reilly, Women \& Babies Program, Sunnybrook Health Sciences Centre, Toronto, Ontario, Canada; maureen.reilly@sunnybrook.ca

Received 21 February 2020 Revised 20 October 2020 Accepted 21 October 2020 Published Online First 24 November 2020

\section{Linked}

- http://dx.doi.org/10.1136/ fetalneonatal-2020-319355

Check for updates

(C) Author(s) (or their employer(s)) 2021. No commercial re-use. See rights and permissions. Published by BMJ.

To cite: Vohra S, Reilly M,

Rac VE, et al. Arch Dis Child Fetal Neonatal Ed

2021:106:F118-F124.

\begin{abstract}
Objective Informed consent is standard in research. International guidelines allow for research without prior consent in emergent situations, such as neonatal resuscitation. Research without prior consent was incorporated in the Vermont Oxford Network Heat Loss Prevention Trial. We evaluated whether significant differences in outcomes exist based on the consent method.
\end{abstract}

Design Subgroup analysis of infants enrolled in a randomised controlled trial conducted from 2004 to 2010.

Setting A multicentre trial with 38 participating centres.

Participants Infants born 24-27 weeks of gestation. 3048 infants assessed, 2231 excluded due to fetal congenital anomalies, failure to obtain consent or gestation less than 24 weeks. 817 randomised, 4 withdrew consent, total of 813 analysed.

Main outcome measure The difference in mortality between consent groups.

Results No significant differences were found in mortality at 36 weeks $(80.2 \%, 77.4 \%, p=0.492)$ or 6 months corrected gestational age $(80.7 \%, 79.7 \%$, $p=0.765)$. Infants enrolled after informed consent were more likely to have mothers who had received antenatal steroids (95.2\%, 84.0\%, $p<0.0001)$. They also had significantly higher Apgar scores at $1(5.0,4.4$, $p=0.019), 5(7.3,6.7, p=0.025)$ and $10 \min (7.5,6.3$, $\mathrm{p}=0.0003)$.

Conclusions and relevance Research without prior consent resulted in the inclusion of infants with different baseline characteristics than those enrolled after informed consent. There were no significant differences in mortality. Significantly higher Apgar scores in the informed consent group suggest that some of the sicker infants would have been excluded from enrolment under informed consent. Research without prior consent should be considered in neonatal resuscitation research.

\section{INTRODUCTION}

Informed consent from an individual or their representative, in conjunction with research ethics committee (REC) oversight and approval, is the ethical standard for participation in research. However, in emergent situations, it is not always possible or even desirable to obtain informed consent, and limiting participation based on this

\section{What is already known on this topic?}

Informed consent is the standard for research. When applied to resuscitation research, this requirement may lead to the exclusion of vulnerable infants.

\section{What this study adds?}

Research without prior consent included sicker infants potentially excluded from enrolment under informed consent. Research without prior consent should be considered in neonatal resuscitation research.

requirement can result in the systematic exclusion of potential participants from research for whom consent would never be possible. ${ }^{1-3}$ The SUPPORT trial identified the risk of population bias where requiring prenatal consent led to the enrolment of a non-representative sample of participants excluding some vulnerable infants who would have been eligible for trial participation if there had been time to obtain informed consent. ${ }^{4}$ Unfortunately, populations incapable of providing informed consent are often vulnerable and are the very populations whose quality of care the research aims to improve. ${ }^{356} \mathrm{As}$ medical progress is based on research, the standard of individual informed consent may delay scientific advancement and deprive vulnerable populations of research advances that are the most relevant to their health.

An evolving discussion questions whether traditional informed consent is always required or appropriate in certain situations. ${ }^{5-9}$ Many have suggested alternatives to traditional consent. ${ }^{1-35610}$ Dickert et $a l^{9}$ highlight the need to recognise contextspecific limitations to consent and propose a spectrum of potential patient or surrogate involvement. The suggested spectrum of consent ranges from complete waiver, simple opt-in/opt-out, broadcast consent and 'staged involvement'. ${ }^{9}$ Faden et al ${ }^{10}$ propose a Common Purpose Framework system that would guide the appropriate form of consent to be used. This system would streamline which form of consent could be administered based on 
where the research activities fall in relation to a threshold of negative effect on outcomes or patient values.

International guidelines exist that present the possibility of conducting research without prior consent in specific situations such that individuals incapable of providing informed consent are not denied the potential benefits of research. ${ }^{1-3}$ The guidelines on ethical research in human subjects outlined in the Declaration of Helsinki have been adopted internationally and state that in any research on human beings, each potential participant must be adequately informed of the aims, methods, sources of funding, any possible conflicts of interest and institutional affiliations regarding the study. ${ }^{11}$ The Declaration of Helsinki and other existing international guidelines also describe specific circumstances under which it is ethical to conduct research without prior consent to facilitate research in emergency situations and to prevent the systematic exclusion of those unable to consent (table 1).

The acceptance of research without prior consent may help combat the issue of informed consent in emergent situations by allowing a proxy to determine in which situations duress may confound the process of informed consent. We propose that research without prior consent is an appropriate and ethical approach to be used in trials testing interventions applied in the immediate newborn period. We incorporated the option of research without prior consent in the Vermont Oxford Network (VON) Heat Loss Prevention (HeLP) Trial, a multicentre randomised controlled trial (RCT) that investigated the effect of polyethylene occlusive wrap applied immediately after birth on mortality in infants born $24+0 / 7$ to $27+6 / 7$ weeks of gestation. ${ }^{12}$ The VON HeLP Trial compared two interventions (standard care vs occlusive wrap) ${ }^{13}$ and met the criteria for the use of research without prior consent (table 2). In this paper, we aimed to compare the primary outcome of mortality along with various maternal and neonatal demographic characteristics between patients enrolled with and without prior consent in the VON HeLP Trial to determine whether significant differences in demographics or outcomes exist between patients based on the consent method used.

\section{METHODS}

The methods of the VON HeLP Trial have been described in detail elsewhere. ${ }^{12} 14$ The number of infants assessed for eligibility and subsequently randomised is summarised in online supplementary appendix A, figure 1. Characteristics of the centres that participated are available in online supplementary appendix B. In this multicentre RCT, the only difference in care between the experimental and control groups was the use of the polyethylene occlusive wrap applied immediately after birth in the intervention group with a primary outcome of all-cause mortality at 36 weeks and 6 months corrected gestational age. With regard to consent, two different forms were available to all participating centres; antenatal informed consent and research without prior informed consent. All parents of infants enrolled without prior consent were approached at an appropriate time after enrolment and informed of the study. Individual RECs decided if consent to submit study data was required or not. In all cases, parents had the option of removing their infant from the study at any time.

Maternal and infant characteristics were compared between the informed consent and no prior consent groups. Apgar scores at 1,5 and $10 \mathrm{~min}$, and temperatures at baseline and poststabilisation, and delivery room temperature were analysed. Mortality at 36 weeks and 6 months corrected gestational age were compared across all patients as well as between the two consent groups.

Descriptive statistics were calculated for all variables of interest. Continuous measures were summarised using means and SD, whereas categorical measures were summarised using counts and percentages. As the data involved patients from multiple hospitals, all $\mathrm{p}$ values presented in the paper account for site differences. Statistical comparisons between consent groups were run using linear models (adjusting for the correlation among observations taken at the same site) for continuous variables and generalised estimating equation models for categorical ones. For continuous measures, the Shapiro-Wilk test was used to assess normality. Where the distribution was non-normal, a non-parametric regression model was run to compare consent groups. For Apgar scores, in addition to comparisons at each time point, a model was run to assess change over time between groups. Patients with missing data were not included in the final analyses. All analyses were carried out using SAS V.9.3 (SAS Institute). The analyses in this paper are considered supplementary to the main analyses carried out in the HeLP trial and therefore no adjustments for multiple testing have been carried out.

\section{Patient involvement}

One of the co-principal investigators sought the input of her institution's neonatal intensive care unit (NICU) Family Advisory Committee to discuss the research question and specifically, the research approach. The NICU Family Advisory Committee fully supported the use of research without prior consent in this particular study. Education sessions were then held with the NICU team who, with the Family Advisory Committee, together supported the application to their institution's Health Research Ethics Board.

\section{RESULTS}

Eight hundred and thirteen infants were enrolled in the study. The data from eight infants were removed from the main analysis due to errors in randomisation. The data from four infants $(0.5 \%)$ were removed due to withdrawal of consent; three were enrolled in the wrap group and one was enrolled in the standard of care group. All participating centres, in conjunction with their RECs, implemented their preferred form of consent. Across all 38 participating centres, a total of $668(83 \%)$ infants were enrolled after informed consent and 133 (17\%) from 4 centres (3 USA and 1 Canadian) were enrolled without prior consent. All four were approved by their REC and were level 3 or 4 NICUs. The three US sites implemented research without prior consent for all eligible infants in the study. At the fourth site, located in Canada, the REC allowed only eligible infants born within 24 hours of maternal admission to hospital to be enrolled without prior consent. If the mother had not delivered 24 hours after admission, the parents were approached for informed consent as the REC felt that birth was no longer emergent. In both the wrap and no wrap groups, $17 \%$ of infants were enrolled without prior consent and 83\% were enrolled after informed consent (online supplementary appendix A).

Maternal characteristics between the consent groups are seen in table 3. No significant differences were found between the groups concerning prenatal care, maternal race, rupture of membranes $(\mathrm{ROM})>24$ hours, chorioamnionitis, the maternal temperature prior to delivery or the occurrence of vaginal deliveries. However, significant differences were found in the use of antenatal steroids and the level of maternal education. Mothers of infants randomised after informed consent received antenatal 
Declaration of Helsinki-Ethical Principles for Medical Research Involving Human Subjects (2013) Human Services (HHS). Office for Human Research Protections $(2016)^{21}$

US Food and Drug Administration: 21CFR50.24 (2018)
- A serious threat to the prospective participant requires immediate intervention; and

- either no standard efficacious care exists or the research offers a real possibility of direct benefit to the participant in comparison with standard care; and

- either the risk of harm is not greater than that involved in standard efficacious care or it is clearly justified by the direct benefits to the participant; and

- the prospective participant is unconscious or lacks the capacity to understand risks, methods and purposes of the research; and

- third party authorisation cannot be secured in sufficient time, despite diligent and documented efforts to do so; and

no relevant prior directive by the participant is known to exist.

Informed Consent

- Research involving subjects who are physically or mentally incapable of giving consent done only if their condition is a necessary characteristic of research group.

- Must seek informed consent from the legally authorised representative.

- If no representative available and research cannot be delayed, can proceed without informed consent but state specific reasons for involving these subjects in the study and need approval of research ethics committee.

- Obtain consent to remain in study as soon as possible

Waiver or alteration of the requirements for obtaining informed consent from adult subjects can occur under any of the following three provisions:

1. Public benefit or service programmes: an REC can waive the requirement to obtain informed consent under the U.S. Department of Health and Human Services (HHS) regulations with the following conditions met:

1. the research could not practicably be carried out without the waiver or alteration; and

2. the research or demonstration project is to be conducted by or subject to the approval of state or local government officials and is designed to study, evaluate or otherwise examine:

1. public benefit or service programmes;

2. procedures for obtaining benefits or services under those programmes;

3. possible changes in or alternatives to those programmes or procedures; or

4. possible changes in methods or levels of payment for benefits or services under those programmes.

2. Research in general: an REC may waive the requirement of informed consent with the following four conditions met:

1. the research involves no more than minimal risk to the subjects;

2. the waiver or alteration will not adversely affect the rights and welfare of the subjects;

3. the research could not practicably be carried out without the waiver or alteration; and

4. whenever appropriate, the subjects will be provided with additional pertinent information after participation.

3. Research in emergency settings: an REC may waive the requirement for obtaining informed consent if the requirements of the HHS Secretarial waiver are met.

For research involving children, an REC may waive the requirements for obtaining parental or guardian permission under any of the following

1. The REC makes and documents the required findings as described above.

2. The REC determines that a research protocol is designed to study conditions in children or a subject population for which parental or guardian permission is not a reasonable requirement to protect the subjects (eg, neglected or abused children), and the following two additional criteria are also met:

1. an appropriate mechanism is in place to protect the children, and

2. the waiver is not inconsistent with federal, state or local law. REC may waive the requirement for obtaining parental or guardian permission if the research involves more than minimal risk to the child subjects.

Exception from informed consent requirements for emergency research:

a. REC (with the concurrence of a licensed physician who is a member of or consultant to the REC and who is not otherwise participating in the clinical investigation) finds and documents each of the following:

1. The human subjects are in a life-threatening situation, available treatments are unproven or unsatisfactory, and the collection of valid scientific evidence, which may include evidence obtained through randomised placebo-controlled investigations, is necessary to determine the safety and effectiveness of particular interventions.

2. Obtaining informed consent is not feasible because:

i. The subjects will not be able to give their informed consent as a result of their medical condition.

ii. The intervention under investigation must be administered before consent from the subjects' legally authorised representatives is feasible.

iii. There is no reasonable way to identify prospectively the individuals likely to become eligible for participation in the clinical investigation.

3. Participation in the research holds out the prospect of direct benefit to the subjects because:

i. Subjects are facing a life-threatening situation that necessitates intervention.

ii. Appropriate animal and other preclinical studies have been conducted, and the information derived from those studies and related evidence support the potential for the intervention to provide a direct benefit to the individual subjects.

iii. Risks associated with the investigation are reasonable in relation to what is known about the medical condition of the potential class of subjects, the risks and benefits of standard therapy, if any, and what is known about the risks and benefits of the proposed intervention or activity.

4. The clinical investigation could not practicably be carried out without the waiver. 
Table 1 Continued

Canada Tri-Council Policy Statement: Ethical Conduct for

Research Involving Humans $(2014)^{22}$

Same as Declaration of Helsinki

\section{Alterations to Consent Requirements}

The research ethics board (REB) may approve research that involves an alteration to the requirements for consent if the following apply:

a. the research involves no more than minimal risk to the participants;

b. the alteration to consent requirements is unlikely to adversely affect the welfare of participants;

c. it is impossible or impracticable to carry out the research and to address the research question properly, given the research design, if the prior consent of participants is required;

d. in the case of a proposed alteration, the precise nature and extent of any proposed alteration is defined; and

e. the plan to provide a debriefing (if any), which may also offer participants the possibility of refusing consent and/or withdrawing data and/or human biological materials.

Consent for Research in Individual Medical Emergencies

Subject to all applicable legal and regulatory requirements, research involving medical emergencies shall be conducted only if it addresses the emergency needs of the individuals involved, and then only in accordance with criteria established in advance of such research by the REB. The REB may allow research that involves medical emergencies to be carried out without the consent of participants or of their authorised third party, if all of the following apply:

a. a serious threat to the prospective participant requires immediate intervention

b. either no standard efficacious care exists or the research offers a realistic possibility of direct benefit to the participant in comparison with standard care;

c. either the risk is not greater than that involved in standard efficacious care or it is clearly justified by the prospect for direct benefits to the participant;

d. the prospective participant is unconscious or lacks capacity to understand the risks, methods and purposes of the research project;

e. third party authorisation cannot be secured in sufficient time, despite diligent and documented efforts to do so; and

f. no relevant prior directive by the participant is known to exist.

When a previously incapacitated participant regains decision-making capacity, or when an authorised third party is found, consent shall be sought promptly for continuation in the project and for subsequent examinations or tests related to the research project.

Declaration of Helsinki ${ }^{11} \quad$ a serious threat to the prospective participant requires immediate intervention; and

- either no standard efficacious care exists or the research offers a real possibility of direct benefit to the participant in comparison with standard care; and

- either the risk of harm is not greater than that involved in standard efficacious care or it is clearly justified by the direct benefits to the participant; and

the prospective participant is unconscious or lacks the capacity to understand risks, methods and purposes of the research; and

- third party authorisation cannot be secured in sufficient time, despite diligent and documented efforts to do so; and

- no relevant prior directive by the participant is known to exist.

US Department of Health and Human Services (2005)
- The research involves no more than minimal risk to the subjects.

- The waiver or alteration will not adversely affect the rights and welfare of the subjects.

- The research could not practicably be carried out without the waiver or alteration.

- Whenever appropriate, the subjects will be provided with additional pertinent information after participation.

FDA Final rules (1996) Available treatments are unproven or unsatisfactory.

- The research cannot practicably be carried out otherwise and is necessary to determine the safety and effectiveness of the intervention.

- It is not feasible to obtain informed consent from the patient or the patient's legal representative.

- The risks and benefits of the experimental procedure are reasonable compared with those associated with the patient's medical condition and standard therapy.

- Additional protections such as consultation with the community, public disclosure of the study design and attendant risks prior to its commencement and public disclosure of study results when complete.

- FDA will also review the protocol design and other information on the proposed therapy before the study is allowed to proceed.

Same as Declaration of Helsinki.
Canada Tri-Council Policy

Statement: Ethical Conduct for

Research Involving Humans

(2010) steroids more frequently $(95.2 \%$ vs $84.0 \%, \mathrm{p}<0.0001)$ than the group enrolled without prior consent. Mothers of infants enrolled without prior consent were more likely to have received some college education compared with mothers enrolled after informed consent $(58.8 \%$ vs $40.1 \%, \mathrm{p}<0.0004)$.

Table 4 lists the neonatal characteristics of the infants in each consent group. No significant differences were found between the groups concerning birth weight, gestational age, sex, race, multiple births or secondary outcomes including bronchopulmonary dysplasia (BPD), retinopathy of prematurity, intraventricular haemorrhage (IVH) and periventricular leucomalacia (PVL). There were however significant differences between the consent groups in Apgar scores at $1(p=0.019), 5(p=0.025)$ and $10 \mathrm{~min}(\mathrm{p}=0.0003)$ where infants enrolled without prior consent had significantly lower Apgar scores compared with the informed consent group. The informed consent group also had a greater increase over time in their Apgar scores $(p=0.043)$. The baseline $(p=0.0008)$, post stabilisation axillary $(p=0.002)$ and delivery room $(p=0.290)$ temperatures were significantly higher for premature newborns in the group without prior consent.

There were no significant differences in mortality at 36 weeks and 6 months corrected gestational age (table 5).

\section{DISCUSSION}

Challenges around informed consent are highlighted in emergency care research where patient surrogates are available, yet barriers to truly informed consent still exist. ${ }^{9}$ The current method of seeking consent from parents of sick neonates may exacerbate parental distress and thereby affect the legitimacy of the decisions made in situations of real stress. ${ }^{15}$ In one study, although $52 \%$ of parents felt full prospective informed consent 
Table 2 Evaluation of criteria for research without prior consent and their applicability to the Vermont Oxford Network Heat Loss Prevention (HeLP) Trial

\begin{tabular}{|c|c|}
\hline Criteria & Applicability to HeLP Trial \\
\hline $\begin{array}{l}\text { A serious threat to the prospective } \\
\text { participant requires immediate } \\
\text { intervention }\end{array}$ & $\begin{array}{l}\text { Premature delivery-women present } \\
\text { emergently } \\
\text { Hypothermia is an independent risk } \\
\text { factor for mortality in premature } \\
\text { infants. }^{9-12} 14-17 \\
\text { Hypothermia remains exceedingly } \\
\text { prevalent. }{ }^{9}\end{array}$ \\
\hline $\begin{array}{l}\text { No standard efficacious care exists or } \\
\text { research offers a real possibility of direct } \\
\text { benefit }\end{array}$ & $\begin{array}{l}\text { Three RCTs and five historical } \\
\text { controlled trials (HCTs) show } \\
\text { differences for admission } \\
\text { temperatures between wrapped and } \\
\text { unwrapped infants. }{ }^{1{ }^{18}-20} 2324 \\
\text { Clinical equipoise remains. }{ }^{2526}\end{array}$ \\
\hline $\begin{array}{l}\text { Risk of harm is not greater than that } \\
\text { involved in standard efficacious care }\end{array}$ & $\begin{array}{l}\text { No evidence of harm based on } \\
\text { clinical trials and routine use in some } \\
\text { NICUs. }\end{array}$ \\
\hline $\begin{array}{l}\text { The prospective participant is } \\
\text { unconscious or lacks the capacity to } \\
\text { understand the research }\end{array}$ & - Not applicable (infant is not yet born). \\
\hline Third party consent cannot be secured & $\begin{array}{l}\text { Insufficient time if emergent delivery. } \\
\text { Consent is not unfettered from duress } \\
\text { (and therefore not truly 'consensual'). }\end{array}$ \\
\hline $\begin{array}{l}\text { No relevant prior directive by the } \\
\text { participant is known to exist }\end{array}$ & - Not applicable (infant not yet born). \\
\hline
\end{tabular}

was necessary in emergency situations, $28 \%$ felt pressure to consent. ${ }^{16}$ We propose it is preferable to share the burden of responsibility with the institution and its REC and involve parents at a time when it is appropriate to do so.

While research without prior consent is not new, we feel it is underutilised in neonatal resuscitation research. ${ }^{17} 18$ The use of research without prior consent in the VON HeLP multicentre RCT provides an example of an ethical solution to the dilemma of obtaining truly informed consent under the pressures of an emergent premature delivery. All participating centres, in conjunction with their RECs, implemented their preferred form of consent. The level of risk is a key determinant as to whether research without prior consent can be applied under existing guidance. In the VON HeLP multicentre RCT, a minimal risk intervention of applying a wrap was studied, therefore the option of research without prior consent was offered to all participating centres. The ultimate decision for proceeding without informed consent was left to the individual RECs. In the SUPPORT trial, waiver of consent was not incorporated. Of 2826 eligible women, 21.2\% were not even approached for consent with the most common reasons being an inability to obtain consent from the mother due to active labour, young maternal age or a pre-existing mental or physical health condition that precluded approach and lack of time before delivery. ${ }^{19}$ Other reasons included the availability of study staff, not being aware of admission and language barriers. Rich et $a l^{4}$ discuss criteria for consent in a clinical trial and argue that waiver of consent in the SUPPORT trial could have been carried out and should be considered for minimal risk trials with interventions in the delivery room or shortly after birth. They also acknowledge that additional research and review are needed regarding moderate-risk trials. The parents of 4 of 137 (3.0\%) infants enrolled without prior consent requested their data be removed from the study, which may suggest a low rate of disapproval with the process of enrolling infants without prior consent. The acceptance of research without prior consent has been reported in other studies exploring methods of consent in an emergency setting. ${ }^{116}$

The analyses conducted in this paper demonstrate that research without prior consent did not result in significant differences in mortality. The Apgar scores of those in the informed consent group were significantly higher than those in the group without prior consent implying that those infants were born in better condition, likely a result of a less acute obstetrical condition and therefore presenting the opportunity for informed consent. Similarly, higher antenatal steroid exposure in the informed consent group suggests a longer time period between presentation and delivery, allowing time for steroid administration and informed consent. In emergent situations, neither the administration of steroids nor the process of informed consent can occur. Our findings are further corroborated by Rich and colleagues' analysis in which infants whose mothers were not approached for consent, and were therefore not enrolled in the SUPPORT trial, also had significantly lower Apgar scores and required more interventions in the delivery room than infants who were enrolled. This again suggests that the sicker infants were excluded from the trial. They found that infants born to women who were not approached for consent were almost six times more likely to have not received antenatal steroid therapy, were more likely to be immature and were significantly less likely to receive prenatal care compared with infants born to women who were approached for trial participation. Enrolled infants appeared to have significantly lower rates of BPD, IVH/PVL and death than infants who were eligible but not enrolled. However, after controlling for the infants' demographic characteristics, the differences in clinical outcomes were no longer significant, suggesting that the demographic characteristics rather than the enrolment status explain the improved outcomes in enrolled infants. ${ }^{4}$ We analysed the same clinical outcomes in all infants enrolled in our trial and also found no significant differences between consent groups. If prospective informed consent affects

Table 3 Maternal characteristics

\begin{tabular}{|c|c|c|c|}
\hline Maternal characteristics & No prior consent & Informed consent & P value comparing consent groups \\
\hline Prenatal care & $128 / 133(96.2 \%)$ & $644 / 667(96.6 \%)$ & 0.814 \\
\hline Rupture of Membranes (ROM) $>24$ hours & $32 / 130(24.6 \%)$ & $211 / 660(32.0 \%)$ & 0.420 \\
\hline Chorioamnionitis & 18/121 (14.9\%) & $136 / 633(21.5 \%)$ & 0.282 \\
\hline Temperature prior to delivery $\left({ }^{\circ} \mathrm{C}\right)$, mean (SD) & $36.8(0.5)$ & $36.9(0.9)$ & 0.006 \\
\hline Antenatal steroids & $110 / 131(84.0 \%)$ & $635 / 667(95.2 \%)$ & $<0.0001$ \\
\hline Vaginal delivery & $45 / 133(33.8 \%)$ & $207 / 668(31.0 \%)$ & 0.611 \\
\hline Race (Caucasian) & $81 / 133(60.9 \%)$ & $375 / 665(56.4 \%)$ & 0.34 \\
\hline Maternal education (college education) & $60 / 102(58.8 \%)$ & $254 / 663(40.1 \%)$ & 0.0004 \\
\hline
\end{tabular}

Bolded $\mathrm{p}$ values indicate statistically significant differences between consent groups 
Table 4 Neonatal characteristics

\begin{tabular}{|c|c|c|c|}
\hline Neonatal characteristics & No prior consent & Informed consent & P value comparing consent groups \\
\hline Birth weight (g), mean (SD) & $804.4(227.0)$ & $811.4(197.2)$ & 0.451 \\
\hline Gestational age (weeks), mean (SD) & $25.5(1.2)$ & $25.7(1.2)$ & 0.09 \\
\hline Sex & & & 0.803 \\
\hline Male & $72 / 133(54.1 \%)$ & $355 / 668(53.1 \%)$ & \\
\hline Female & $61 / 133(45.9 \%)$ & $313 / 668(46.9 \%)$ & \\
\hline Race & & & 0.911 \\
\hline Black & $36 / 133(27.1 \%)$ & $182 / 665(27.4 \%)$ & \\
\hline White & $81 / 133(60.9 \%)$ & $375 / 665(56.4 \%)$ & \\
\hline Asian or Pacific Islander & $11 / 133(8.3 \%)$ & $73 / 665(11.7 \%)$ & \\
\hline Native American & $0 \%$ & $2 / 665(0.3 \%)$ & \\
\hline Other & $5 / 133(3.8 \%)$ & $28 / 665(4.2 \%)$ & \\
\hline Multiple births & $26 / 133(19.6 \%)$ & $133 / 668(19.9 \%)$ & 0.865 \\
\hline \multicolumn{4}{|l|}{ Apgar scores, mean (SD) } \\
\hline $1 \mathrm{~min}$ & $4.4(2.4)$ & $5.0(2.3)$ & 0.019 \\
\hline $5 \mathrm{~min}$ & $6.7(2.4)$ & $7.3(1.8)$ & 0.025 \\
\hline $10 \min$ & $6.3(2.7)$ & $7.5(2.1)$ & 0.0002 \\
\hline \multicolumn{4}{|l|}{ Temperature ${ }^{\circ} \mathrm{C}$, mean (SD) } \\
\hline Baseline axillary & 36. $3(0.9)$ & $35.9(1.0)$ & 0.0008 \\
\hline Post stabilisation axillary & $36.6(0.9)$ & $36.3(1.1)$ & 0.002 \\
\hline Delivery room & $23.6(2.5)$ & $23.9(2.0)$ & 0.29 \\
\hline Bronchopulmonary dysplasia & $65 / 117(55.6 \%)$ & $301 / 585(51.5 \%)$ & 0.417 \\
\hline Retinopathy of prematurity & $16 / 89(18.0 \%)$ & 99/517 (19.1\%) & 0.794 \\
\hline Intraventricular haemorrhage & $18 / 128(14.1 \%)$ & $72 / 625(11.5 \%)$ & 0.419 \\
\hline Periventricular leucomalacia & $5 / 128(3.91 \%)$ & $33 / 623(5.30 \%)$ & 0.513 \\
\hline
\end{tabular}

the population enrolled in studies, outcomes observed may not be applicable to the general population.

If the entire VON HeLP multicentre RCT had been conducted without prior consent, a larger proportion of infants' representative of the patient population served would have been represented. This would better lend itself to finding a statistically significant difference should one exist. This trial and others would have also likely been completed in a shorter time frame with faster dissemination of results contributing to medical progress. The CATheter Infections in CHildren (CATCH) trial attributed their large target sample size and subsequent generalisable results to the use of research without prior consent. ${ }^{1}$ While parents may have initial concerns about the deferred consent model, they support the model in emergency trials so long as the intervention applied is part of routine clinical practice. ${ }^{16}$ If RCTs are restricted to low-risk individuals, then the chance of finding statistically significant differences in treatment groups is low or even impossible as the individuals themselves are unlikely to develop the condition under study, thus providing results that are not generalisable to the entire population.

The finding of higher baseline temperatures in the group without prior consent is difficult to understand, since patients in this group had lower Apgar scores. This finding may be due to a centre effect such that centres using research

\begin{tabular}{llll}
\hline $\begin{array}{l}\text { Table } 5 \\
\text { age }\end{array}$ & Survival at 36 weeks and 6 months corrected gestational \\
\hline & No prior consent & Informed consent & P value \\
\hline $\begin{array}{l}\text { Survival at } 36 \text { weeks } \\
103 / 133(77.4 \%)\end{array}$ & $534 / 666(80.2 \%)$ & 0.492 \\
$\begin{array}{l}\text { Survival at } 6 \text { months } \\
\text { corrected gestational } \\
\text { age }\end{array}$ & $106 / 133(79.7 \%)$ & $538 / 667(80.7 \%)$ & 0.765 \\
\hline
\end{tabular}

without prior consent may have been generally better at thermoregulation than those using informed consent. Only by randomising consent method within centres or using a robust cluster randomised trial could the effect on outcome be properly assessed. The VON HeLP trial did not randomise centres to different types of consent, as randomising centres to an approach they may be unfamiliar or uncomfortable with would not have been feasible. Only four centres chose to use research without prior consent resulting in $17 \%$ of infants being enrolled in the RCT without prior consent. The proportion of infants enrolled without prior consent was equally represented in both the randomised groups. Compared with the SUPPORT trial where 1316 enrolled infants were compared with 3053 eligible infants who were not enrolled, our study is smaller in size however highlights the same finding that research without prior consent does not result in significant differences in mortality and can facilitate the inclusion of potentially sicker infants. All statistical analyses presented in the paper account for site differences as clinical routines and/or patients may be different between different centres.

The issue of research without prior consent for neonatal resuscitation research is important and timely. ${ }^{5620}$ The use of research without prior consent is not to 'bypass' informed consent when this option is available and appropriate but rather to enable research in emergency situations including in neonatal resuscitation research. It represents a context-specific strategy to enable representative enrolment in emergency care research and can still facilitate the involvement of parents at an appropriate time. If it is not pursued more vigorously, many newly born infants will be denied the benefits of research. We encourage researchers and RECs to consider research without prior consent when conducting neonatal resuscitation research. 


\section{Author affiliations}

'Pediatrics, University of Alberta, Faculty of Medicine and Dentistry, Edmonton, Alberta, Canada

${ }^{2}$ Women and Babies Program, Sunnybrook Health Sciences Centre, Toronto, Ontario, Canada

${ }^{3}$ Institute of Health Policy Management and Evaluation, University of Toronto, Toronto, Ontario, Canada

${ }^{4}$ Newborn-Perinatal Medicine, Vermont Oxford Network, Burlington, Vermont, USA

${ }^{5}$ Cone Health, Women's Hospital of Greensboro, Greensboro, North Carolina, USA

${ }^{6}$ Pediatrics, Dalhousie University, Halifax, Nova Scotia, Canada

${ }^{7}$ Research Design and Biostatistics, Sunnybrook Research Institute, Toronto, Ontario, Canada

${ }^{8}$ Pediatrics, University of Vermont, Burlington, Vermont, USA

${ }^{9}$ Pediatrics, University of Toronto, Toronto, Ontario, Canada

Funding Funded by the Canadian Institutes of Health Research (MCT 71137 HELP Vohra) and the Stollery Children's Hospital Foundation (Edmonton, Canada; G599000746). SV receives salary support as an Alberta Innovates-Health Solutions Health Scholar (G118160495). RS receives salary support as the director of trials and follow-up at Vermont Oxford Network.

Competing interests None declared.

Patient consent for publication Not required.

Provenance and peer review Not commissioned; externally peer reviewed.

Data availability statement Data may be available upon request.

Supplemental material This content has been supplied by the author(s). It has not been vetted by BMJ Publishing Group Limited (BMJ) and may not have been peer-reviewed. Any opinions or recommendations discussed are solely those of the author(s) and are not endorsed by BMJ. BMJ disclaims all liability and responsibility arising from any reliance placed on the content. Where the content includes any translated material, BMJ does not warrant the accuracy and reliability of the translations (including but not limited to local regulations, clinical guidelines, terminology, drug names and drug dosages), and is not responsible for any error and/or omissions arising from translation and adaptation or otherwise.

ORCID iD

Sunita Vohra http://orcid.org/0000-0002-6210-7933

\section{REFERENCES}

1 Harron K, Woolfall K, Dwan K, et al. Deferred consent for randomized controlled trials in emergency care settings. Pediatrics 2015;136:e1316-22.

2 Biros MH. Research without consent: exception from and waiver of informed consent in resuscitation research. Sci Eng Ethics 2007;13:361-9.

3 Eltorki M, Uleryk E, Freedman SB. Waiver of informed consent in pediatric resuscitation research: a systematic review. Acad Emerg Med 2013;20:822-34.

4 Rich W, Finer NN, Gantz MG, et al. Enrollment of extremely low birth weight infants in a clinical research study may not be representative. Pediatrics 2012;129:480-4.

5 Janvier A, Farlow B. The ethics of neonatal research: an ethicist's and a parents' perspective. Semin Fetal Neonatal Med 2015;20:436-41.
6 DeMauro SB, Foglia EE, Schmidt B. The ethics of neonatal research: a Trialists' perspective. Semin Fetal Neonatal Med 2015;20:431-5.

7 McKinney RE, Beskow LM, Ford DE, et al. Use of altered informed consent in pragmatic clinical research. Clin Trials 2015:12:494-502.

8 Feltman DM. Re: delivery room research: when does poor quality evidence become an ethical issue? Pediatrics 2015;135:e1368-9.

9 Dickert NW, Brown J, Cairns CB, et al. Confronting ethical and regulatory challenges of emergency care research with conscious patients. Ann Emerg Med 2016;67:538-45

10 Faden RR, Beauchamp TL, Kass NE. Informed consent, comparative effectiveness, and learning health care. N Engl J Med 2014;370:766-8.

11 Wma Declaration of Helsinki: ethical principles for medical research involving human subjects, 2004. Available: http://www.wma.net/e/policy/b3.htm [Accessed 6 Oct 2005].

12 Vohra S, Reilly M, Rac VE, et al. Study protocol for multicentre randomized controlled trial of help (heat loss prevention) in the delivery room. Contemp Clin Trials 2013;36:54-60.

13 Vohra S, Reilly M. Equipoise with respect to wrapping premature newborns immediately after delivery. Paediatr Child Health 2006;11:270

14 Reilly MC, Vohra S, Rac VE, et al. Randomized trial of occlusive wrap for heat loss prevention in preterm infants. J Pediatr 2015;166:262-8.

15 Manning DJ. Presumed consent in emergency neonatal research.J Med Ethics 2000;26:249-53.

16 McCarthy KN, Ryan NC, O'Shea DT, et al. Parental opinion of consent in neonatal research. Arch Dis Child Fetal Neonatal Ed 2019;104:F409-14.

17 Vohra S, Frent G, Campbell V, et al. Effect of polyethylene occlusive skin wrapping on heat loss in very low birth weight infants at delivery: a randomized trial. J Pediatr 1999:134:547-51.

18 Vohra S, Roberts RS, Zhang B, et al. Heat loss prevention (help) in the delivery room: a randomized controlled trial of polyethylene occlusive skin wrapping in very preterm infants. J Pediatr 2004;145:750-3.

19 Rich WD, Auten KJ, Gantz MG, et al. Antenatal consent in the support trial: challenges, costs, and representative enrollment. Pediatrics 2010;126:e215-21.

20 Woolfall K, Frith L, Dawson A, et al. Fifteen-minute consultation: an evidence-based approach to research without prior consent (deferred consent) in neonatal and paediatric critical care trials. Arch Dis Child Educ Pract Ed 2016;101:49-53.

21 U.S. Department of Health \& Human Services. Office for human research protections. informed consent FAQs, 2016. Available: https://www.hhs.gov/ohrp/regulations-andpolicy/guidance/faq/informed-consent/index.html [Accessed 4 Dec 2018].

22 Tri-Council Policy Statement. Ethical conduct for research involving humans (TCPS2), 2014. Available: http://www. pre.ethics.gc.ca/eng/policy-politique/initiatives/tcps2eptc2/Default/ [Accessed 4 Dec 2018].

23 Johanson RB, Spencer SA, Rolfe P, et al. Effect of post-delivery care on neonatal body temperature. Acta Paediatr 1992:81:859-63.

24 Hazan J, Maag U, Chessex P. Association between hypothermia and mortality rate of premature infants--revisited. Am J Obstet Gynecol 1991:164:111-2.

25 Silverman WA, Fertig JW, Berger AP. The influence of the thermal environment upon the survival of newly born premature infants. Pediatrics 1958:22:876-85.

26 Beinder E, Trojan A, Bucher HU, et al. Control of skin blood flow in pre- and full-term infants. Biol Neonate 1994;65:7-15.

27 Knobel RB, Wimmer JE, Holbert D. Heat loss prevention for preterm infants in the delivery room. J Perinatol 2005;25:304-8. 